\title{
versants
}

\section{La memoria histórica en España: un pasado más actual que nunca}

\author{
Walther L. BERNECKER \\ Universität Erlangen-Nürnberg
}

\begin{abstract}
El artículo tiene por tema el desarrollo de la "memoria histórica" desde la transición a la democracia hasta el presente, resaltando cómo la Guerra Civil y el franquismo han condicionado la conciencia de varias generaciones españolas a lo largo de los últimos ochenta años. Analiza la postura de los diferentes gobiernos nacionales desde 1975, discute la importancia del "pacto de silencio" en la transición, explica la recuperación de la memoria colectiva a finales del siglo xx y contrapone la postura "oficial" de los gobiernos a las iniciativas de la sociedad civil. El estudio pone un énfasis especial en dos aspectos concretos: por un lado, la labor de organizaciones extragubernamentales como la Asociación para la Recuperación de la Memoria Histórica, por otro la exhumación de los restos de Francisco Franco de la basílica del Valle de los Caídos en 2019.
\end{abstract}

Keyword: memoria histórica, olvido, pacto de silencio, Valle de los Caídos, exhumación de Franco

\section{Memoria y olvido}

Memoria y recuerdo parecen haberse convertido, en las últimas décadas, en un meta-concepto o incluso en un paradigma de las ciencias culturales (Welzer 2004). Y como siempre, cuando un concepto está de moda coyunturalmente, rápidamente surgen los críticos (Kablitz 2006) que se oponen a la "historia de la memoria" como la viene practicando desde hace años, entre otros, Jan Assmann. De un tiempo a esta parte viene teniendo lugar un debate intenso y controversial sobre la relación entre memoria e historia. El historiador francés Pierre Nora ha explicado detalladamente la diferencia fundamental entre memoria e historia. Nora, uno de los creadores del concepto "lugares de la memoria", argumenta que la diferencia entre las dos formas históricas de conmemoración consiste en que la memoria siempre "es de un grupo vivo", que puede ser (mal) usada "para todo tipo de manipulaciones», y que representa un «vínculo» al pasado, «vivido en un presente sempiterno». La memoria sirve, en primer lugar, para fortalecer la unión de un determinado grupo social. La ciencia histórica, en cambio, tiene «vocación de universalidad». Por medio de «análisis y argumentación crítica» intenta establecer una separación entre pasado y presente (Nora 1990).

No todos los autores diferencian tan estrictamente entre historia y memoria, pues también la reconstrucción del pasado como la practican los historiadores, acontece siempre en el presente. Entretanto, en muchos países se ha desarrollado un amplio panorama en torno a los diferentes discursos 
de la memoria histórica. En lo que sigue, se presentarán algunos de estos discursos, concentrándose la exposición en el caso español (Dejung 2008).

Indudablemente, la Guerra Civil española ha condicionado en gran manera, hasta hoy, la conciencia de las generaciones posteriores. Incluso se puede decir que acaso no haya habido en los tiempos contemporáneos otro hecho histórico que, como la Guerra Civil española, haya sido piedra de toque de lealtades políticas e ideológicas y divisoria de posiciones existenciales. Las consecuencias de la guerra marcaron la vida de millones de ciudadanos; la guerra es considerada por la mayoría de los españoles como el acontecimiento más importante de la historia de su país para comprender la España actual. La Guerra Civil introdujo en la sociedad española una cesura traumática que hace de la guerra la coyuntura decisiva de la historia española en el siglo xx (Aróstegui I987).

La reconciliación, imprescindible para reconstruir un país devastado por la Guerra Civil, fue rechazada por los vencedores. La sustituyó una durísima represión de posguerra, que ahondó aún más las divisiones de la guerra. Una represión sin piedad, que se cifra en decenas de miles de ejecuciones, de encarcelamientos durante años, de depuraciones, de exilio exterior o de ostracismo interior, una represión, que no dejó lugar a dudas que la Guerra Civil había sido una guerra social. Josep Benet (I986: II3) ha afirmado que de los muchos crímenes cometidos por Franco, el mayor fue su comportamiento al finalizar la guerra.

Los cautos intentos de abrir, en las décadas siguientes, el régimen franquista a los vencidos, realizados por los que progresivamente comprendieron que la reconciliación solo podía ser efectiva en el marco de un pluralismo que les reconociera el derecho a su identidad, tropezaron con la monolítica negativa constante, rotunda y visceral del régimen, cada vez menos respaldado por la sociedad, ni siquiera por la Iglesia que se apartó cada vez más del Estado y en I97I pidió públicamente perdón «porque no supimos a su tiempo ser verdaderos ministros de reconciliación en el seno de nuestro pueblo dividido».

En el siglo xx español, la damnatio historiae formó parte de los intentos sistemáticos del régimen franquista de eliminar todo tipo de memoria histórica que no se dejaba encuadrar en la tradición del Alzamiento Nacional del I8 de julio I936: físicamente, asesinando a los líderes del lado republicano; políticamente, repartiendo el poder sin compromisos entre los vencedores; intelectualmente por medio de censura y prohibiciones; propagandísticamente con indoctrinaciones unilaterales; culturalmente, eliminando los símbolos de aquella aparente "Anti-España" que había sido obligada a capitular incondicionalmente después de una larga guerra de casi tres años de duración. 
A la destrucción de la memoria de aquella España vencida, pronto vendría a sumarse la necesidad de tener que borrar de la memoria de los hombres las huellas de los propios crímenes. El régimen de Franco habrá sido, como se ha afirmado, tradicionalista; pero se trataba de un tradicionalismo percibido de una forma extremadamente selectiva y unilateral, que echaba al olvido tanto como conservaba. El régimen de Franco nunca ha estado legitimado democráticamente. El recuerdo de la lucha por la libertad, llevada a cabo entre 1936 y 1939 con una crueldad desconocida, podría haber surtido consecuencias desestabilizadoras. Para la ciencia histórica, amordazada políticamente durante mucho tiempo, esto supuso la necesidad de practicar la historiografía no como una ciencia crítica, sino como legitimación del régimen vencedor. La Guerra Civil había de ser presentada como "cruzada" nacional y antibolchevique y como "guerra de liberación nacional". Durante décadas, libros críticos con el régimen solo podían ser publicados y vendidos en el extranjero.

El lugar de memoria más importante del franquismo es el Valle de los Caídos, situado en las inmediaciones del Escorial en la Sierra de Guadarrama. En su monumentalidad, representa la ideología fundacional del régimen franquista. En primer lugar, es un monumento de la victoria y un símbolo del sistema triunfal en la Guerra Civil. Franco mismo eligió el lugar donde iba a erigirse el monumento de los caídos y de la victoria. El monumento fue concebido como símbolo de la nueva unidad de la España nacional. La cercanía con el Escorial debía subrayar, por un lado, la estrecha conexión entre Estado e Iglesia y, por otro, la tradición imperial y contrarreformadora.

La construcción del monumento fue supervisada en todos los detalles por Franco mismo. Arte y arquitectura eran usados como instrumentos de dominación (Alted Vigil 1984; Equipo Reseña 1977). Monumentalismo e historicismo eran las tendencias arquitectónicas de la época, y a ellas se atuvo el primer arquitecto del Monumento Nacional, Pedro Muguruza. Para paliar la falta de mano de obra, se recurrió a prisioneros de guerra, que según la idea del jesuita José A. Pérez del Pulgar podrían "redimir" sus penas en la construcción del monumento. Además, el trabajo en las obras del Valle podía ser interpretado como una especie de reeducación: los enemigos de antaño colaboraban en la construcción del monumento más importante de la "Nueva España", contribuyendo así simbólicamente y de hecho a la construcción de una España cuyos valores básicos habían combatido en la guerra (Lafuente 2003).

El Valle de los Caídos tiene un carácter sepulcral. Pero el recuerdo a los muertos fue ensalzado míticamente, haciendo de los héroes del "Movimiento" ejemplos de una causa: futuras generaciones debían ser fortalecidas en la convicción de lo correcto (Sueiro I983; Méndez I982). Se ponía de mani- 
fiesto la razón de la muerte de los caídos como sacrificio por el pueblo español. La mayor virtud del individuo era, pues, la disposición a sacrificarse por su pueblo y su patria.

\section{La memoria histórica en la transición y la democracia}

Historiadores y publicistas siempre han resaltado que solo en un Estado democrático, sin trabas intelectuales ni censura política, se podría llegar a una interpretación crítica de la Guerra Civil o de los primeros años negros del franquismo. En la transición de la dictadura a la democracia se abrieron, después de 1975, algunos archivos; los libros sobre la Guerra Civil tuvieron un tremendo auge. Entre historiadores se hablaba de la "recuperación de la historia". Por esta se entendía tanto el estudio del pasado reciente y su integración en la memoria colectiva como parte insoslayable de la identidad histórica, como el enlace con anteriores tradiciones historiográficas y políticas, interrumpidas por la larga época de la dictadura franquista (Casanova 2008).

El enorme interés, después de 1975, por publicaciones históricas, politológicas y sociológicas y, concretamente, sobre la Guerra Civil, era expresión de un extendido deseo de obtener más información. Era de esperar, pues, que el 50 aniversario del comienzo (1986) y del final de la guerra (1989) sería motivo de múltiples actividades para satisfacer el interés de los ciudadanos. Pero comparado con la enorme importancia que esta guerra tiene para la España de hoy, los actos fueron más bien limitados. Además, la mayoría de las conmemoraciones formó parte del dominio más bien "distanciado" de los historiadores. La España "oficial” apenas se dejaba oír. En junio de 1986, pocas semanas antes de la fecha exacta del cincuentenario, iban a tener lugar elecciones parlamentarias, y el PSOE tenía que luchar por conservar su mayoría absoluta. En esta situación, políticamente un tanto delicada, los electores del centro y de la derecha moderada no debían ser asustados llamando la atención, públicamente y a través de medios de comunicación de masa, sobre la división de la sociedad española en los años treinta. Por aquel entonces, el Partido Socialista había formado parte del espectro izquierdista de la vida política del país. Además, no se podría haber impedido un debate público en el que también se habría discutido la co-responsabilidad del más importante partido obrero en el ocaso de la democracia. (Por cierto: El silencio oficial también se apoderó de los políticos conservadores de la opositora Alianza Popular.)

La única declaración del Palacio de La Moncloa -que Felipe González hizo como Presidente de Gobierno de todos los españoles, y no como secretario general del PSOE- decía que «la Guerra Civil no es un acontecimiento conmemorable, por más que para quienes la vivieron y sufrieron constitu- 
yera un episodio determinante en su propia trayectoria biográfica». Añadía que era «definitivamente historia, parte de la memoria de los españoles y de su experiencia colectiva». El comunicado agregaba: «Pero no tiene ya -ni debe tenerla- presencia viva en la realidad de un país cuya conciencia moral última se basa en los principios de la libertad y de la tolerancia».

Indudablemente, tales afirmaciones deben verse en relación con la construcción de la democracia después de 1975 y con la palabra clave de la transición: consenso. La experiencia traumática de la Guerra Civil, de violencia brutal y de división social ha sido, implícitamente, el trasfondo de muchas posturas y medidas en la fase de la transición: De la aceptación de la Monarquía por parte de socialistas, de las posturas moderadas de los comunistas, de la colaboración de todas las fuerzas políticas en la elaboración de la nueva Constitución. La nueva democracia no debía edificarse por una parte de la sociedad contra la voluntad de otra, sino participando todos los campos políticos en esta labor. Pero condición previa era la reconciliación de los antiguos bandos enemigos. No se debían saldar viejas cuentas aún no resueltas, sino debían acabar definitivamente las enemistades y luchas del pasado.

Este deseo de reconciliación y el miedo de volver a abrir viejas heridas habrá llevado a los socialistas a no conmemorar oficialmente el cincuentenario de la Guerra Civil, incluso a reprimirlo, y a mostrar políticamente comprensión por el "otro" lado de antaño. El comunicado de La Moncloa añadía que el Gobierno quería «honrar y enaltecer la memoria de todos los que, en todo tiempo, contribuyeron con su esfuerzo, y muchos de ellos con su vida, a la defensa de la libertad y de la democracia en España», y que recordaba «con respeto a quienes, desde posiciones distintas a las de la España democrática, lucharon por una sociedad diferente, a la que también muchos sacrificaron su propia existencia». El Gobierno manifestaba su esperanza de que

nunca más, por ninguna razón, por ninguna causa, vuelva el espectro de la guerra y del odio a recorrer nuestro país, a ensombrecer nuestra conciencia y a destruir nuestra libertad. Por todo ello el Gobierno expresa también su deseo de que el 50 aniversario de la Guerra Civil selle definitivamente la reconciliación de los españoles (El País, I9.07.1986: I7).

De alguna manera, vencedores y vencidos habían conservado sus papeles. Los socialistas en el Gobierno de I982 a I996 recurrieron al peso heredado del miedo como consecuencia de la guerra, para asegurar su cautela política, para no realizar ningún cambio radical que posiblemente hubiera podido poner en peligro la estabilidad del sistema. La estabilidad política lograda en España tuvo su precio político y moral. La paz sociopolítica debía ser pagada. La supervivencia del sistema simbólico franquista recuerda que la reforma política partía de un pacto elaborado en las instituciones autori- 
tarias, y que finalmente condujo a la transición. De acuerdo con este carácter transitorio, las Fuerzas Armadas pasaron sin ningún tipo de purga desde la dictadura al postfranquismo.

El hecho de que no hubo una clara ruptura democrática con la dictadura franquista ha arrojado una sombra sobre aquellas áreas del pasado que son llamadas "lugares de la memoria". La transición fue una especie de "pacto de honor" por el cual se compensó a los franquistas por desalojar el poder no haciendo uso político en los años después de 1975 del pasado, de la Guerra Civil y la represión franquista. Esto es válido para los gobiernos conservadores entre 1977 y I982, pero no es menos válido para el PSOE: con su renuncia a la historia, la socialdemocracia española perpetuó la pérdida de la memoria a la que fue obligada la población española en la dictadura. En ambos casos, la marginalización y la represión de la historia sirvieron para estabilizar las estructuras de poder vigentes.

En su estudio sobre ideología e historia, Alberto Reig Tapia (I986) ha llamado la atención sobre el hecho que la "manipulación" propagandística en torno a la Guerra Civil no desapareció con la muerte del general Franco y el fin de su régimen. El largo tiempo transcurrido bajo la dominación franquista y la poderosa influencia que la propaganda de su régimen ejerció a lo largo de 40 años determinaron que haya "cristalizado" en amplias capas de la población española una visión parcial y deformada de la guerra y del terror.

Aparte de las reflexiones presentadas hasta ahora, otra causa importante de la "eliminación" oficial de la Guerra Civil radicó en el consenso ideológico que primó durante aquellos años en la mayoría de la sociedad española, y que puede ser calificado con los conceptos de modernización y europeización (Köhler 1986; Bernecker 1990). El trasfondo de esta fe en el progreso, del consumismo extrovertido y de una euro-euforia sin precedentes fue, en los años de la transición, un complejo de inferioridad, justamente con respecto a este progreso y a esta Europa, de la que el régimen franquista primero se había distanciado (con el lema: España es diferente) y de la que más tarde fue marginado y excluido por motivos políticos. Filósofos, escritores y políticos se han planteado y replanteado la pregunta del por qué del "atraso" de España. En este debate, la Guerra Civil es el evento histórico por el que se ponía más claramente de manifiesto el atraso de España, era el punto final en toda una serie de intentos malogrados de modernización.

La consecuencia de la Guerra Civil, la instalación del régimen franquista, llevó después de 1945 a la exclusión de España de la comunidad de naciones y al boicot económico. Inferioridad, aislamiento y división entre vencedores y vencidos: Estos fenómenos se asocian en España con la Guerra Civil y sus secuelas. La apertura del país hacia la democracia, hacia el progreso y hacia Europa fue un distanciamiento consciente de este pasado no deseado. 
Sobre la Guerra Civil, y más aún sobre los primeros años del franquismo, se tendió una capa de silencio en los discursos políticos, posiblemente porque la generación de la transición no consideró oportuno hablar sobre una época tan conflictiva de su historia. La importancia que desde la esfera estatal se dio al "progreso" hizo aparecer disfuncional la evocación de las épocas interpretadas como "negativas". En aras de la mentalidad reconciliadora también se sacrificaron aquellos actos conmemorativos que muchos habían esperado del Gobierno en I986 o I989. Más bien, el lema proclamado hacia todos los lados por igual, rezaba: «Nunca más!» La Guerra Civil se enjuició como "tragedia”, como crisis que evocaba el derrumbe de todos los valores de la convivencia humana.

\section{La recuperación de la memoria colectiva}

En los últimos años, se han venido planteando una serie de discusiones entre quienes consideran que la democracia española se ha asentado en el olvido, y los que piensan que las medidas destinadas a la reparación de las víctimas han sido suficientes y que los arreglos fundacionales de la democracia obligan a no remover los aspectos más espinosos del pasado, sino a respetarlos por el bien de la convivencia pacífica entre los españoles.

A finales de 1995, el gobierno español concedió la nacionalidad española a petición del parlamento a todos los miembros de las Brigadas Internacionales que aún vivían. Casi sesenta años después del comienzo de la Guerra Civil, el gobierno de Madrid cumplía una promesa hecha a los interbrigadistas todavía en la guerra (en noviembre de 1938) por el entonces jefe de gobierno Juan Negrín. Durante décadas, la dictadura de Franco había impedido el cumplimiento de esta promesa; y tampoco en los años de la transición los políticos españoles se habían ocupado de aquella promesa. Cuando, en I995, la Asociación de Amigos de las Brigadas Internacionales promovió finalmente la concesión de la nacionalidad, todos los partidos del parlamento estuvieron dispuestos a cumplir con esta petición. En la exposición de motivos de la ley se decía que casi sesenta años después de comenzada la Guerra Civil y veinte tras el comienzo de la transición, había pasado suficiente tiempo para que todos los españoles amantes de la democracia y la libertad pudieran contemplar serenamente aquella parte de su pasado que durante cuarenta años había significado una herida abierta (Mardones I996; Muñoz Molina I995). El que todas las fuerzas políticas españolas hicieran este reconocimiento histórico a los interbrigadistas, demostró de manera impresionante la voluntad de los españoles de reconciliarse en su interior.

Con excepción de este gesto hacia los interbrigadistas, el gobierno en muchos casos se comportó de manera muy reservada cuando se trataba de implementar iniciativas concretas de políticas de la memoria. En este com- 
portamiento, sus críticos ven uno de los mayores déficits de la transición que dañó a la cultura política del país. Otro indicador de la imperfección de la transición es, en esta interpretación, el tratamiento de los familiares de los "desaparecidos" en el bando republicano durante la guerra. Pues mientras que el lado franquista, inmediatamente después de la guerra, pudo identificar a sus muertos y enterrarlos con todos los honores, algo parecido no se ha hecho hasta hoy con el lado republicano. Se estima que unos $\mathbf{3} 30.000$ republicanos muertos siguen enterrados en fosas anónimas. Desde hace 25 años, los familiares han presentado en vano solicitudes a los gobiernos democráticos. No fue sino en el año 2002, después de haber intervenido la Comisión de Derechos Humanos de las Naciones Unidas, que empezó a discutirse seriamente sobre esta cuestión; los primeros muertos republicanos fueron exhumados y enterrados de nuevo en fosas familiares. Y no fue sino a finales de 2002 que el Parlamento promulgó una resolución exigiendo del gobierno que apoyara financieramente las acciones de búsqueda y reconociera a las víctimas políticas del franquismo como tales. Pero el gobernante Partido Popular logró impedir que se condenara explícitamente el golpe militar de I936; además, se decía en la resolución, que el reconocimiento de las víctimas no debía ser usado para volver a abrir viejas heridas. Por lo tanto, no se debía acusar a los golpistas de 1936.

Entretanto, el recuerdo de las muchas víctimas de la Guerra Civil y la dictadura ha vuelto a la memoria colectiva (Vilarós I998; Medina Domínguez 200I; Resina 200o). Se empezó a discutir si aquel proverbial "pacto de silencio" en el discurso político había existido de verdad, si se había basado en un consenso colectivo o si había sido impuesto por las élites políticas. En contra de las interpretaciones críticas, Santos Juliá afirma que la memoria histórica solo fue relegada de la política, pero no de la memoria colectiva. El «consenso del silencio» habría seguido a la sabia convicción de excluir la historia del debate político, abriendo al mismo tiempo el camino para un trato equilibrado del pasado por la historiografía (Juliá I996, 2002, 2006).

Además, la cuestión de la represión franquista se adueñó de congresos y publicaciones científicas (Bernecker 2003). Nuevo material de archivo hizo posible descubrir el estremecedor sistematismo del aparato estatal de represión que, hasta comienzos de los años cincuenta, fue responsable de unos I40.000 muertos, explotando además a centenares de miles de republicanos en más de cien campos de trabajo (Juliá 2004; Elordi 2002; Torres 2002; Torres 2002; Casanova 2002; Serrano \& Serrano 2002).

En vista de la postura gubernamental de rechazar cualquier iniciativa memorialística, empezó en otoño del año 2000 una iniciativa local en Priaranza del Bierzo (Castilla-León) con las exhumaciones de cadáveres. El primer proyecto, realizado con ayuda de arqueólogos profesionales, buscaba exhumar a trece "desaparecidos" en la Guerra Civil. El enorme eco mediá- 
tico llevó a la fundación de la Asociación para la Recuperación de la Memoria Histórica (ARMH) y de plataformas similares con presencia en Internet. La Asociación fue fundada por el periodista Emilio Silva que buscaba los restos de su abuelo desaparecido (Silva 2005). Desde su fundación, la Asociación lucha por aclarar asesinatos políticos y ejecuciones en masa perpetrados por los rebeldes durante la Guerra Civil contra los defensores de la República. Pero debido al gran número de muertos no identificados, la Asociación no dispone de los medios necesarios para las exhumaciones.

Hasta el día de hoy, la inmensa mayoría de las exhumaciones realizadas, se ha hecho gracias a la iniciativa de organizaciones civiles formadas por familiares y voluntarios que no han cejado en su empeño de dar una sepultura digna a los suyos. El Estado español tiene de hecho la obligación de impulsar un Plan Nacional de búsqueda de los desaparecidos y acometer las exhumaciones. Así se lo han recordado en múltiples ocasiones diversas organizaciones de las Naciones Unidas, p. ej. el Consejo de Derechos Humanos, el Grupo de Trabajo contra las Desapariciones Forzadas y los relatores de la ONU para la promoción de los derechos a la verdad, la justicia y la reparación. Todos ellos han criticado a España por el abandono que han sufrido y siguen sufriendo las víctimas del franquismo.

A principios del siglo xxi, durante el gobierno del Partido Popular, se fundaron varias organizaciones de víctimas de la represión. Por su protagonismo mediático e implantación territorial, destaca la ya mencionada Asociación para la Recuperación de la Memoria Histórica. Sus actividades se centran en la localización y exhumación de fosas comunes. En segundo lugar destaca también el Foro por la Memoria, creado en 2002, que se enfrenta en sus objetivos básicos a la ARMH, ya que considera que el traslado de restos de las fosas comunes contribuye al olvido. Hasta 2005, fueron surgiendo más de I70 (!) organizaciones destinadas a la memoria histórica en su sentido más lato (Gálvez Biesca 2006). Se puede decir que la apelación a la "memoria histórica" se convirtió, a finales del siglo xx, en el lema reivindicativo por excelencia de la izquierda y de los nacionalistas, mientras que los conservadores rechazaron y rechazan ese afán por "recuperar" la memoria tildándolo de "revanchista" y equiparando la demanda de justicia retrospectiva con el ánimo de venganza. A la idea de "memoria", el PP contrapuso la de "concordia". También trató de equiparar "memoria" con "venganza", volviendo a agitar el fantasma de la Guerra Civil (Aguilar Fernández 2007).

Los diferentes esfuerzos por recuperar un pasado "prohibido" o relegado significan un paso hacia la "normalización" de la conciencia histórica, es decir hacia el acercamiento de las disparidades existentes todavía en la memoria colectiva. Con un retraso de unos 60-80 años se vislumbra una "superación" pública con respecto al trauma más grave de la reciente historia 
española; para las generaciones afectadas directamente, esta "superación" llega tarde en la mayoría de los casos.

La enmienda aprobada en la Comisión Constitucional del Congreso de los Diputados el 20 de noviembre de 2002, en la que se condenaba el golpe de Estado del i8 de julio de I936 (sin citarlo explícitamente) contra la legalidad republicana, perseguía la finalidad de «mantener el espíritu de concordia y de reconciliación» de la Constitución de 1978. Distintos parlamentarios insistieron en la interpretación que con esta decisión se enterraban definitivamente las «dos Españas»-Antonio Machado-y se abría el camino a los deseos de «paz, piedad y perdón» -Manuel Azaña- (Bedmar González 2003: I3). No obstante, algunas publicaciones llegan a unas conclusiones muy críticas:

En teoría, la iniciativa de los parlamentarios se reduce a recoger de manera más que limitada, parca y tardía las aspiraciones de una buena parte de la sociedad española hastiada de olvidos, de reconciliación sin memoria y de amnistías que supusieron borrón y cuenta nueva, sin atender a razones de justicia ni de reparaciones morales (Bedmar González 2003: I4).

Con el "descubrimiento" de los crímenes, cometidos desde el comienzo de la Guerra Civil en nombre del Estado franquista, empezó ahora una confrontación pública con un pasado que desde la perspectiva de la historiografía ya no albergaba grandes secretos. Pero el público en general se adentró en un campo que hasta entonces había sido esquivado conscientemente por sus imponderabilidades políticas. Este proceso es de importancia ante todo a nivel individual. Bien es verdad que tampoco ahora se trata de aclarar jurídicamente las violaciones de derechos humanos cometidas a lo largo de la dictadura. Pero según las voces de los familiares que lloran la pérdida no aclarada de un allegado, no se trata de cometer venganza, sino más bien de aclarar los asesinatos y de recibir un gesto simbólico. Para muchos, el reconocimiento público de la injusticia cometida parece ser un gesto suficiente para hacer sus paces con el pasado más reciente.

En el presente, la memoria sigue ganando batallas en la lucha contra el olvido. Durante varios años se multiplicaron los signos de que el recuerdo a las víctimas de la Guerra Civil y la dictadura había sido recuperado por la opinión pública. En otoño de 2002 fue inaugurada una exposición dedicada al destino de los exiliados republicanos que, a causa de la gran afluencia de público, tuvo que ser prolongada.

En cuanto a la relación entre debate público sobre la represión franquista y la historiografía sobre la Guerra Civil, merece la pena citar la tesis de Santos Juliá, quien pone en duda que en España jamás haya existido «un pacto de silencio». Más bien, en el discurso público la memoria siempre había estado presente. Fue la memoria la que dio, como permanente amones- 
tación, el decisivo impulso para negociar en la primera fase de la transición las amnistías y hacer posible aquel olvido que eliminó la Guerra Civil como argumento de la competencia política. Juliá resalta la prehistoria mental de la transición, cuando las fuerzas moderadas de dentro y fuera del régimen se habían acercado ya mucho antes de la muerte del dictador preparando, en cierta manera, mentalmente el posterior discurso de la reconciliación. El signo más claro de este acercamiento fue la paulatina re-interpretación de la Guerra Civil, que fue vista como una desgracia colectiva de la que ambos lados eran igualmente responsables. Detrás del actual boom de la memoria no se encuentra pues, el rechazo de un "pacto de silencio» (inexistente de todas maneras), sino el final del consenso de la memoria que implicaba una repartición más o menos "igual” de la culpa (Juliá 2002).

Esta observación puede probarse empíricamente, pues en las publicaciones de los últimos diez a veinte años se ha acentuado, más que en la fase precedente, la ilegitimidad del golpe militar de 1936 y la sistemática represión por la parte franquista. La represión franquista, tanto en la Guerra Civil como en la posguerra, se ha convertido en una nueva rama de la historiografía. Por otro lado, también se formó un grupo interpretativo revisionista. Autores como Pío Moa o César Vidal, que achacan a la izquierda prácticamente toda la responsabilidad de la Guerra Civil, han tenido notable éxito de ventas con sus múltiples publicaciones de extrema derecha (Moa I999, 2004a, 2004b; Vidal 2003). Se puede decir, pues, que la relativa homogeneidad interpretativa de la transición, de nuevo ha dado lugar a una discrepancia interpretativa mucho más acentuada.

Que el pasado represor franquista se haya convertido en los últimos años en un tema tan importante tiene que ver con que el Partido Popular bajo José María Aznar formó el gobierno de 1996 a 2004. Desde un principio, los conservadores se comportaron en cuestiones históricas y de política histórica como defensores de un legado conservador, inmóvil. Frente a prácticamente todas las iniciativas de la oposición de honrar el recuerdo de los exiliados de la Guerra Civil o de conceder fondos para recompensarlos, el partido en el gobierno reaccionó con un rechazo -supuestamente, porque los textos de las propuestas de ley contenían condenas del golpe militar de I936-. Además, el PP insistía en la idea que la Guerra Civil era una fase "superada" de la historia española. En su segundo mandato (2000-2004), el gobierno Aznar rechazó más de 25 iniciativas parlamentarias de este tipo. Por otro lado, esta postura gubernamental llevó a actividades de la sociedad civil - generalmente apoyadas por la oposición- como la fundación de la Asociación para la Recuperación de la Memoria Histórica.

Hasta finales del gobierno Aznar en marzo de 2004, el ejecutivo obstaculizó casi todo tipo de trabajo de la memoria que podría interpretarse como una condena de los crímenes franquistas. No sería sino el gobierno socia- 
lista de José Luis Rodríguez Zapatero, que asumió su función en marzo de 2004 después de los atentados terroristas de Madrid, el que finalmente cambió la política de la memoria. El nuevo interés suscitado en España por la represión franquista y el debate público sobre estos temas fueron síntomas de un cambio histórico y epocal. Poco a poco desapareció la imagen de la dictadura que había ofrecido la maquinaria propagandística del franquismo y que se conservó durante mucho tiempo también en la democracia. Los historiadores tienen la obligación de aportar luz que ayude a desentrañar los episodios trágicos de la Guerra Civil y de la dictadura franquista; pero la rememoración de estos episodios trágicos no pretende resaltar las divisiones ni azuzar revanchas, sino reafirmar valores supremos como unión, solidaridad, paz y libertad que eviten nuevos conflictos. Los múltiples y serios trabajos de investigación de los últimos años contribuyen a eliminar los fantasmas del pasado y a defender el derecho a la memoria y a la recuperación de la Historia que posee cualquier sociedad (Subirats 2002). El trabajo de historia y memoria críticas sobre un pasado dictatorial resulta esencial cuando se trata de construir la democracia, cuando el establecimiento de un sistema democrático arraigado es la tarea colectiva de toda una sociedad (Aguilar Fernández 2002).

Por lo general, existe un consenso acerca de que el trabajo de la memoria tiene impulsos positivos para la consolidación democrática de una sociedad, ya que crea confianza en las instituciones del Estado de derecho. En el caso español, la nueva popularidad de la memoria, tan asiduamente promulgada en los últimos años, ha dificultado las perspectivas con respecto a un consenso de la memoria, a una unánime condena del pasado más reciente. La experiencia de los últimos años enseña que en España, según parece, un trato crítico de la historia solo es posible por el precio de una acentuada confrontación política y de la formación de dos campos ideológicos opuestos. ¿Confirma este resultado a posteriori la inteligencia política de los responsables de la transición que optaron por no usar la historia como argumento político después de la muerte de Franco?

La mal llamada «Ley de Memoria Histórica», que en realidad se refiere solo al reconocimiento y la ampliación de los derechos de quienes «padecieron persecución o violencia durante la guerra y la dictadura», anunciada repetidas veces a partir de 2004, finalmente fue aprobada por el Consejo de Ministros en verano de 2006, después de haber sido postergada una y otra vez. El proyecto de ley preveía que el parlamento español debía elegir con una mayoría de tres quintas partes un gremio de expertos, un tribunal de cinco notables, que debía decidir durante un año sobre las solicitudes de ser reconocido como víctima del franquismo y recibir compensación financiera. La rehabilitación moral debía ser decidida, por lo tanto, partiendo de solicitudes individuales. Debido a las mayorías parlamentarias, este tribunal 
de notables solo podía crearse con el asentimiento del PP; pero a principios de 2007, el PP dio a entender que rechazaba definitivamente la institución de un gremio así. Eso significó que la parte central del proyecto de ley no tenía ninguna perspectiva de ser promulgada por vía parlamentaria. Además, el proyecto de ley no equivalía a la reivindicación de muchas organizaciones de la sociedad civil, de declarar in toto ilegales las sentencias políticas de los tribunales militares y de orden público franquistas. El jefe de gobierno, Rodríguez Zapatero, declaró que el gobierno español no podía anular las sentencias franquistas en su totalidad, ya que semejante acto equivalía a una «ruptura del orden legal»-una interpretación rechazada por renombrados juristas constitucionales-. Además, el proyecto de ley preveía ampliar el círculo de las personas con derecho a pensión y compensación por sentencias franquistas. Finalmente, debían alejarse de edificios estatales todos los símbolos que glorificaban unilateralmente uno de los bandos de la Guerra Civil.

En otoño de 2006 comenzó el debate parlamentario, y pronto se puso de manifiesto que el proyecto de ley no tendría una mayoría parlamentaria en la forma presentada. Los conservadores rechazaron el proyecto en su totalidad, ya que supuestamente volvía a abrir las fosas del pasado. Y los partidos a la izquierda del PSOE y varias organizaciones civiles criticaron el esbozo porque no implicaba todo lo que ellos habían querido conseguir con la ley. Era de prever que el proyecto tendría que ser modificado, si los socialistas querían impedir un fracaso en el parlamento (Moreno 2006).

Finalmente, en primavera de 2007 , la negociación entre los portavoces del PSOE y de Izquierda Unida sacó de su parálisis parlamentaria a la ley. El acuerdo entre los dos partidos declaraba la ilegitimidad de los tribunales y de sus sentencias, dictadas en la Guerra Civil y durante la dictadura por motivos ideológicos o políticos. Según el gobierno, la nulidad de las sentencias por ley quedaba descartada, pues eso correspondía a los tribunales. Pero la declaración de ilegitimidad es tan tajante, que muchas veces ha sido aportada como prueba válida en las reclamaciones de revisión de sentencias que periódicamente llegan al Tribunal Supremo.

Las diferentes interpretaciones dadas a esta imprecisa enmienda confirman las dificultades existentes para armonizar los términos de su dilema: satisfacer las peticiones de los represaliados por el franquismo o mantener los principios de seguridad jurídica, prescripción e irretroactividad restaurados por el ordenamiento constitucional de 1978 (Pradera 2007). La mayoría de los artículos del proyecto de ley se refiere a mejoras de prestaciones, como pensiones, asistencia médica, orfandad, tributación de indemnizaciones y ayudas para localizar e identificar los restos de los fusilados durante y tras la Guerra Civil. Conviene resaltar en este contexto que en los treinta años siguientes al comienzo de la transición ya se resolvieron favorablemen- 
te 574.000 expedientes de pensiones e indemnizaciones destinadas a personas que fueron castigadas injustamente por auxiliar a la República y por oponerse a la dictadura, con un valor de más de I6.00o millones de euros, salidos del erario público (Gallego-Díaz 2007).

Los populares inmediatamente acusaron al Presidente de gobierno de romper los acuerdos de la transición y de promover el revanchismo de los defensores de la legalidad republicana derrotados en la Guerra Civil, mientras que el portavoz de Esquerra Republicana de Catalunya criticaba que el proyecto de ley no alcanzaba "los principios mínimos" exigidos. Por lo menos, la nueva fórmula abría la vía para reclamaciones personales de anulación de sentencias concretas por parte de los afectados.

En septiembre de 2007 todo parecía indicar que la proyectada Ley de Memoria Histórica corría el peligro de naufragar, ya que las pretensiones de Convergéncia, de Izquierda Unida, del Partido Nacionalista Vasco y de Esquerra Republicana de Catalunya eran imposibles de aceptar para el Gobierno en las últimas horas de negociación. Esquerra se descolgó finalmente de la ley, porque esta no anulaba los juicios del franquismo, pero en el último minuto posible el PSOE logró negociar la ley con los demás grupos parlamentarios. En varios puntos el Gobierno tuvo que ceder: ahora se declaran injustas las condenas en la Guerra Civil y en la dictadura impuestas por razones políticas, ideológicas o de creencia religiosa; en la exposición de motivos se condena expresamente al franquismo; los tribunales constituidos durante la Guerra Civil son declarados ilegítimos; las leyes de represión franquistas son derogadas; el Estado está obligado a promover la memoria democrática de la lucha contra el franquismo; se facilita fundamentalmente el acceso a los archivos; el Estado se compromete a intervenir adecuadamente en las exhumaciones.

El PSOE resaltó que la ley no ofendía a nadie, sino que reparaba los daños que sufrieron las víctimas de la Guerra Civil y de la dictadura. Y se hizo en línea con el espíritu de concordia de la transición. El Gobierno no quería reabrir heridas o enfrentar a los españoles. Por eso, estaba interesado en que la ley tuviera el máximo consenso y no solo diera satisfacción a la izquierda. La acertada pretensión del Gobierno de buscar el mayor acuerdo posible para esta norma, de la que solo se han excluido el PP y Esquerra Republicana, ha provocado, sin embargo, que algunas disposiciones resulten extrañas desde el punto de vista jurídico (como la declaración de ilegalidad sin efectos de los juicios del franquismo o la derogación expresa de los bandos de guerra, como si estas disposiciones hubieran seguido en vigor después de la Constitución de 1978). Algunas soluciones parecen timoratas, como la relativa al Valle de los Caídos.

El PP, en su rechazo a la ley, insistió, por el contrario, en que el texto culminaba el ataque de Zapatero a todo lo que representaba la transición. Pero 
en el terreno de lo concreto, el PP finalmente votó a favor de nueve artículos de la ley: los referidos a ayudas concretas a colectivos que aún estaban ayunos de reconocimiento y a la nueva regulación del Valle de los Caídos (Calleja 2009) que se encargaría de rehabilitar la memoria «de todos los caídos en la Guerra Civil y los que sufrieron represión».

Se trata ante todo de una ley de reparación de una situación de inferioridad en que se encontraron durante décadas los que perdieron la guerra, y con la suficiente sensibilidad para no convertirla en una norma maniquea, ya que su campo de aplicación abarca también a las víctimas franquistas. Pero esta interpretación no la comparten todos, ante todo no la comparte el PP. Unos 45 años después de la muerte de Franco, la memoria histórica se ha convertido, en España, en un campo de batalla cultural y político. Las memorias divididas y enfrentadas se refieren a ese pasado que no quiere pasar y con el que el país tendrá que vivir todavía por bastante tiempo.

\section{Memorias confrontadas: la batalla continúa}

En uno de sus escritos, Theodor Adorno dice que dejar hablar al sufrimiento es la condición de toda verdad. Esta reflexión no la hizo suya el PP, que logró el poder en 20II con la presidencia de Mariano Rajoy. Desde entonces -hasta 20I8- el partido y el gobierno se esforzaron en invisibilizar a las víctimas silenciadas de la Guerra Civil y el franquismo, y a imponer una generalizada amnesia social. El gobierno Rajoy eliminó inmediatamente la dotación que la Ley de Memoria Histórica había previsto para financiar exhumaciones en las aproximadamente 2000 fosas que se calcula que existen en España. No hubo un desarrollo en el ejercicio de la Ley; muy al contrario, el gobierno trató de intensificar la desmemoria selectiva que en España se ha practicado durante tanto tiempo, no importando en absoluto los acuerdos internacionales sobre estas materias ratificados por España, como la Convención para la Protección de todas las personas contra las Desapariciones Forzadas, y no importando tampoco el informe del relator de Naciones Unidas en el que se señala que es la ignominia y el olvido lo que se ha incorporado a la normalidad democrática de España.

Reivindicar el derecho y el deber de memoria no es solo poner en el centro un hecho del pasado, sino resignificarlo y asumir las responsabilidades que se derivan del mismo, articular un consenso sobre lo intolerable, y delimitar claramente lo que de ningún modo puede volver a suceder. Las responsabilidades tienen una dimensión temporal que no se agota en el presente; mira hacia el pasado, como ha de mirar hacia el futuro, y trata a todas las víctimas de la misma manera, aunque distinga las distintas violencias de las que cada uno ha sido objeto (Palop 20I7). Quienes defienden una política de la memoria para todas las víctimas, sin exclusión, están convencidos 
de que el examen detenido del pasado es un arma que permite combatir el revisionismo y el negacionismo (tan en boga actualmente) con los que se justifican y se niegan todos los días las atrocidades que se han vivido en España, y de las que muchas personas tienen todavía recuerdos muy vivos. Y saben, además, que las sociedades eligen recordar u olvidar, y el modo en que lo hacen, condiciona totalmente sus opciones de futuro, de manera que sin memoria no puede haber una auténtica cultura democrática, ni puede hablarse, en puridad, de un sistema político legítimo.

Albert Camus dijo una vez sobre la Guerra Civil Española: «Fue en España donde mi generación aprendió que uno puede tener razón y ser derrotado, golpeado; que la fuerza puede destruir el alma y que, a veces, el coraje no tiene recompensa» (apud Santos 2019: II). Pero, a la vista de la España de hoy, no se puede asegurar que el coraje de aquellos combatientes republicanos no consiguiera a largo plazo sus objetivos. Ochenta años después de aquel desastre, la democracia y la libertad por las que la República en guerra había luchado, se han asentado en España, si bien el precio fue muy elevado. El fascismo y el totalitarismo que inspiraron a los vencedores de entonces, pronto quedaron derrotados en Europa, y si bien tardíamente, tras la muerte de Franco, también en España. Y aunque últimamente se hayan producido ciertos retrocesos en la calidad de la democracia, ante todo en lo relativo a la memoria histórica, y aunque perduren sectores de la sociedad española, residuales pero ruidosos, que se resisten a condenar al franquismo, a eliminar todo reconocimiento y homenaje a sus protagonistas, a retirar sus símbolos y dar una justa satisfacción a las demandas de las víctimas, de ese combate también saldrá victoriosa la democracia. Aunque con rémoras, esa victoria ya está ocurriendo. El pasado de la Guerra Civil siempre estuvo presente en España, hoy más que nunca.

Un llamativo ejemplo de las enfrentadas memorias históricas en la España actual es la evidente contradicción en materia de memoria entre la (extrema) derecha y la moderada izquierda socialista del PSOE. Como se sabe, el gobierno de Rajoy había dejado a cero, en la segunda década del siglo xxi, el presupuesto dedicado a la memoria histórica. En 2018, cuando el recién formado gobierno del socialista Pedro Sánchez destinó 15 millones de euros a este propósito en su proyecto de Presupuestos, las críticas del PP arreciaron brutalmente. Casi a diario se podía escuchar cómo los conservadores y los ultraderechistas del nuevo partido Vox pervertían el relato histórico o banalizaban los crímenes del franquismo. Si se generaliza o perpetúa la postura del PP y de Vox -lo que es de temer-, a los familiares de las víctimas se les escapa la última posibilidad de recuperar los restos de sus seres queridos: un durísimo golpe a las personas mayores que solo piden que se cumplan los derechos que les corresponden y que mueren sin obtener ni justicia ni verdad ni reparación. 
A finales de 20I8, la derecha logró desbancar al PSOE del gobierno de Andalucía, donde éste había gobernado 36 años. Si bien el ultraderechista partido Vox no forma parte del nuevo gobierno andaluz, sí está en condiciones de obligar al gobierno de PP y Ciudadanos a ciertas políticas, ya que el Ejecutivo andaluz depende en el Parlamento de Sevilla de los votos de Vox. Así, en febrero de 20I9, se le adjudicó a Vox la presidencia de la Comisión de Cultura y Patrimonio, comisión que se ocupa también de las políticas de Memoria Histórica. Esta mayoría derechista significa que en materia de Memoria Histórica solo se tocarán los temas que la extrema derecha decida y cuando lo decida. El pacto firmado entre PP y Vox para la investidura de Juan María Moreno como presidente del gobierno andaluz recoge la promoción de una «Ley de Concordia que sustituya a la ley de memoria histórica». Vox, y concretamente su presidente Santiago Abascal, desde un principio se ha expresado en términos muy duros contra la Ley de Memoria Histórica y se autodefine como la voz de aquellos que tuvieron padres en el bando nacional y se resisten a tener que hacer una condena de lo que hicieron sus familias.

El trato de la memoria histórica por parte de la derecha después de las elecciones andaluzas de diciembre de 2018 es un presagio de lo que pasaría en caso de alcanzar el bloque derechista el poder en el Estado español. Si la política de la memoria fue esencial para construir la Europa democrática de postguerra tras la derrota del fascismo y nazismo, la derecha europea -al igual que la española - tiende a rechazar el marco europeo de la memoria, subrayando la supuesta "virtud" del nacionalismo y pretendiendo, al mismo tiempo, re-interpretar la historia para ajustarla a sus objetivos políticos. Un ejemplo es la visión histórica del nuevo partido ultraderechista Vox, que usa continuamente la polémica idea de Reconquista que siempre ha sido profundamente ideológica, definiéndola como una lucha de liberación nacional de los españoles por recuperar su territorio. Pero este concepto de Reconquista ha sido rebatido ya repetidas veces por historiadores profesionales, ya que reduce a los musulmanes de Al Andalus a la condición de ocupantes pasajeros de un territorio que no les pertenecía. El uso que hacen Vox y el Partido Popular de la Historia española es político y manipulado, usando ideas nacionalistas, xenófobas y ante todo islamófobas para influir a los españoles la idea que son una gran nación que realizó grandiosas hazañas en el pasado. Franco había sido el primero en hacer abiertamente un uso político de la Reconquista para justificar su golpe de Estado en 1936 contra la República: en la Edad Media, afirmó, se liberó a España de los moros, y él llevaría a cabo una nueva Reconquista para liberar al país de los "rojos" y "ateos". Este pilar conceptual básico de la lectura nacionalcatólica de la Historia de España es utilizado últimamente por la derecha española en general para obstaculizar cualquier acción de Memoria Histórica. 
Otro ejemplo es la revisión interpretativa del Valle de los Caídos y la exhumación de los restos mortales de Franco y su traslado a otra fosa. Los socialistas pretenden, desde hace tiempo, una «reconversión y resignificación» del Valle de los Caídos, apelando al cumplimiento de la Ley de Memoria del año 2007. En concreto, se debe honrar y rehabilitar la memoria de todas las personas fallecidas a consecuencia de la Guerra Civil de 1936-1939 y de las víctimas de la represión política de los casi 40 años de dictadura; fomentar la cultura de la reconciliación y la convivencia; dignificar los restos de las 33.847 personas, de uno y otro bando, que están inhumadas en el Valle en mal estado. El Valle de los Caídos debería dejar de ser en la práctica un "espacio exclusivo" de homenaje a las víctimas de una de las partes implicadas en la Guerra Civil. Hasta hoy, no se ha avanzado en este cometido de "resignificación" por la dura oposición de los intereses de la derecha. Y como era de esperar, la familia Franco se opuso por todos los medios jurídicos y mediáticos a sacar los restos de Franco del mausoleo. La exhumación prevista tuvo que superar los recursos legales de la familia Franco que llevó el asunto hasta el Tribunal Supremo, y la estrategia de sus aliados (la Fundación Francisco Franco, la Asociación del Valle de los Caídos, muchas organizaciones de ultraderecha y neofranquistas...) que diseminaron acciones jurídicas, incluso deteniendo el plan de obras por una supuesta falta de licencia. El responsable de la basílica del Valle, el prior benedictino Santiago Cantera, fue uno de los líderes de la resistencia. El Arzobispado de Madrid no se opuso a la exhumación, pero apeló a un acuerdo entre el Gobierno y la familia Franco. El gobierno socialista de Pedro Sánchez había creído, cuando accedió al poder a mediados de 20I8, que el problema del Valle de los Caídos y de la exhumación de Franco se resolvería "en breve". No fue así. Más bien, el debate sobre el paradero de los restos de Franco movilizó de nuevo a la sociedad española, fracturándola de una manera antes inimaginable, y es un síntoma -quizá el más grave- de lo dividido que está el país aún a 45 años de la muerte del dictador.

Finalmente, el 24 de octubre de 2019, el féretro con los restos de Franco salió de la basílica del Valle de los Caídos, 44 años después de la sepultura de honor del dictador. El nuevo sepulcro de Franco está en el cementerio de Mingorrubio, en El Pardo (Madrid). La salida del ex dictador de la basílica abrió el paraje serrano del Valle a la resignificación, tras haber pasado décadas como polo central de la memoria franquista. El Presidente del gobierno Pedro Sánchez recalcó que la exhumación de Franco ponía fin a una afrenta moral que España arrastraba desde 1975, a saber el enaltecimiento de la figura de un dictador cruel en un espacio público. Se mostró convencido que con este acto España cumplía "consigo misma", señalando que la España actual era fruto del perdón, pero no del olvido. Poco después de la exhumación de Franco, Patrimonio Nacional autorizó la apertura de las criptas del 
Valle de los Caídos donde habían sido enterrados, durante la dictadura, sin el respectivo consentimiento familiar, miles de republicanos.

También después de la exhumación de Franco, los gobiernos locales y regionales del PP seguían y siguen obstaculizando, donde y siempre que pueden, muestras visibles de la memoria histórica. Así, el Consistorio de Madrid decidió, a principios de 2020, retirar las placas con los nombres de casi 3.00o fusilados por el franquismo en Madrid entre los años I939 y 1944. Además, el Ayuntamiento capitalino decidió no incorporar unos versos del poeta Miguel Hernández al Memorial del cementerio de la Almudena concebido para honrar a las víctimas de la Guerra Civil y el franquismo. Con estas decisiones, la derecha hurta a los familiares de las víctimas el justo reconocimiento y, al mismo tiempo, profundiza en la estrategia de confrontación ideológica.

Hasta hoy no hay concordancia entre derecha e izquierda sobre la necesidad de transformar el Valle de los Caídos en un Memorial de las Víctimas de la Guerra Civil, y de momento las partes contrincantes parece que no se pondrán de acuerdo. Independientemente de este ejemplo negativo se debe concluir: cuando se habla de la necesidad de recuperar la memoria histórica, se habla de reivindicar derechos humanos, de exigir justicia y reparación eficaces para las víctimas, de garantizar la dignidad de las personas asesinadas. Se trata, nada menos, que de crear espacios donde la sociedad en general pueda reconciliarse, donde pueda empezar a construir futuros comunes. La memoria, aunque mire al pasado, es siempre futuro.

\section{Bibliografía}

Aguilar Fernández, Paloma, Memoria y olvido de la Guerra Civil española, Madrid, 1996.

—. «Justicia, política y memoria: los legados del franquismo en la transición española», en Las políticas hacia el pasado. Juicios, depuraciones, perdón y olvido en las nuevas democracias, eds. Barahona de Brito, Alexandra, Aguilar Fernández, Paloma \& González Enríquez, Carmen, Madrid, Istmo, 2002, pp. I35-I94.

—. «Los debates sobre la Memoria Histórica», Claves de Razón Práctica, I72, 2007, pp. 64-68.

Alted Vigil, Alicia, Política del Nuevo Estado sobre el patrimonio cultural y la educación durante la Guerra Civil Española, Madrid, Ministerio de Cultura, I984.

Andrés Sanz, Jesús de, «Las estatuas de Franco y la memoria histórica del franquismo», Historia y política, I2, 2004, pp. I6I-I86.

ARMH [Asociación para la Recuperación de la Memoria Histórica]: http:// www.memoriahistorica.org (I.2.20I0) 
Aróstegui, Julio, «Los componentes sociales y políticos», en La guerra civil española. 50 años después, Tuñón de Lara, Manuel, Aróstegui, Julio, Viñas, Ángel, Cardona, Gabriel \& Bricall, Josep M. (eds.), Barcelona, Labor, I987, pp. 45-I22.

Bedmar González, Arcángel, «Las sombras de la historia», en Memoria y olvido sobre la Guerra Civil y la represión franquista, Bedmar González, Arcángel (ed.), Lucena, Ayuntamiento, 2003, p. I3.

Benet, Josep, «Las libertades secuestradas», en La guerra civil española, 50 años después. Una reflexión moral, Tamames, Ramón (ed.), Barcelona: Planeta, I986, pp. IoI-II3.

Benet, Vicente J., «Franco, NO-DO y las conquistas del trabajo», Archivos de la Filmoteca. Materiales para una iconografía de Francisco Franco, Valencia: Generalitat, 2, 42/43, oct. 2002-feb. 2003, pp. 3I-5I.

Bernecker, Walther L., «Entre la historia y la memoria: Segunda República, Guerra Civil española y primer franquismo», Iberoamericana, II, 2003, pp. 227-238.

—. «Spanien und Europa seit dem Bürgerkrieg», Hispanorama, 56, noviembre I990, pp. 2I-3I.

Calleja, José María, El Valle de los Caídos, Madrid, Espasa, 2009.

Casanova, Julián, «Pasado y presente de la Guerra Civil Española», Historia Social, 6o, 2008, pp. II3-I27.

Casanova, Julián (ed.) Morir, matar, sobrevivir. La violencia en la dictadura de Franco, Barcelona, Crítica, 2002.

Cazorla Bertrán, «La Generalitat pagará en Cataluña la localización de fosas», El País, I8.06.2009, p. I7.

Cirici, Alexandre, La estética del franquismo, Barcelona, Gustavo Gili, I977.

Dejung, Christof, «Oral History und kollektives Gedächtnis. Für eine sozialhistorische Erweiterung der Erinnerungsgeschichte», Geschichte und Gesellschaft, 34, 2008, pp. 96-II5.

Del Aguila, Rafael, «Desmemoria y rememoración: la guerra y el franquismo hoy», Historia y Política, I6, 2006, pp. I83-206.

despage [desaparecidos de la Guerra Civil y el Exilio Republicano] (s.a.): http://www.nodo50.org/despage/ (I.2.20I0)

Elordi, Carlos (ed.), Los años difíciles. El testimonio de los protagonistas anónimos de la guerra civil y la posguerra, Madrid, Aguilar, 2002.

Equipo Reseña, La cultura española durante el franquismo, Bilbao, Mensajero, I977.

Gallego-Díaz, Soledad, «Sin estrépito de ley», El País, 27.04.2007, p. I9.

Gálvez Biesca, Sergio, «El proceso de la recuperación de la 'memoria histórica' en España: una aproximación a los movimientos sociales por la memoria», International Journal of Iberian Studies, I, I9, 2006, pp. 25-5I.

Gibson, Ian, En busca de José Antonio, Barcelona, Planeta, I980. 
Gil, Fernando Martínez, «Historia del Alcázar de Toledo», Historia I6, I34, I987, pp. 84-88.

Ginard i Féron, David, «La represión contra los vencidos y los resistentes en la posguerra española (I939-I948)», en Represión política, justicia y reparación, Capellà, Margalida \& Ginard, David (eds.), Palma de Mallorca, Edicions Documenta Balear, 2009, pp. 43-IO2.

Herreros, Isabelo, Mitología de la Cruzada de Franco. El Alcázar de Toledo, Madrid,Vosa, I995.

Ibáñez Fanés, Jordi, «Perdonen que insista sobre la memoria», El País, 20.04.2009, p. 27.

Juliá, Santos, «Raíces y legados de la transición», en Memoria de la transición, Santos, Juliá, Pradera, Javier \& Prieto, Joaquín (eds.), Madrid, Taurus, I996, pp. 679-682.

-. «Echar al olvido. Memoria y amnistía en la transición», Claves de razón práctica, 129, 2002, pp. I4-24.

- «De nuestras memorias y de nuestras miserias», Dossier monográfico de Hispania Nova. Revista de Historia Contemporánea, 7, 2007, pp. 779-798. Disponible en línea: <http://hispanianova.rediris.es>.

-. (ed.), Víctimas de la guerra civil, Madrid, Temas de Hoy, 2004.

-. (ed.), Memoria de la guerra y del franquismo, Madrid, Taurus, 2006.

Junquera, Natalia, «Las autonomías se niegan a asumir la apertura de fosas», El País, I5.5.2009a, p. 20.

—. «Una juez de Zamora, primera en abrir una fosa de la guerra», El País, 27.05.2009b, p. I9.

—. «El tiempo se acaba para las víctimas de Franco», El País, 08.06.2009c, p. 40.

Kablitz, Andreas, «Geschichte - Tradition - Erinnerung? Wider die Subjektivierung der Geschichte», Geschichte und Gesellschaft, 32, 2006, pp. 220237.

Köhler, Holm-Detlev, «Der traumatische Bürgerkrieg», Kommune, II, I986, pp. 26-29.

Lafuente, Isaías, Esclavos por la patria. La explotación de los presos bajo el franquismo, Madrid, Temas de Hoy, 2003.

Llorente Hernández, Ángel, Arte e ideología en el franquismo (I936-I95I), Madrid, Visor, 1995.

Llorente Hernández, Ángel, «La construcción de un mito. La imagen de Franco en las artes plásticas en el primer franquismo (1936-I945)», Archivos de la Filmoteca. Materiales para una iconografía de Francisco Franco, 42/43, I, 2002, pp. 47-75.

Losada, Juan Carlos, Los mitos militares en España: la historia al servicio del poder, Madrid, Biblioteca Nueva, 2005. 
Madalena Calvo, José I., «Los Lugares de Memoria de la guerra civil en un centro de poder: Salamanca, I936-I939», en Historia y memoria de la Guerra Civil. Encuentro de Castilla y León, Vol 2, Aróstegui, Julio (ed.), Valladolid, Junta de Castilla y León, 1988, pp. 487-549.

Mardones, I. G., «Los brigadistas tienen tres años de plazo para pedir la ciudadanía española», El país, o6.03.1996. Disponible en línea: <www. elpais.com/articulo/espana> (I.2.2010).

Martín Pallín, José Antonio, «Los muertos han aprendido a esperar», El País, 20.03.2009, p.3I.

Martínez Bande, José, Los asedios. Madrid, San Martín, 1983.

Medina Domínguez, Alberto, Exorcismos de la historia. Políticas y poéticas de la melancolía en la España de la transición, Madrid, Libertarias, 200I.

Méndez, Diego, El Valle de los Caídos. Idea, proyecto y construcción. Madrid, Fundación Nacional Francisco Franco, 1982.

Moa, Pío, Los orígenes de la Guerra Civil española, Madrid, Encuentro, 1999.

-. Los crímenes de la Guerra Civil y otras polémicas, Madrid, La Esfera de los Libros. 2004a.

-. Los mitos de la Guerra Civil, Madrid, La Esfera de los Libros, 2004b.

Molinero, Carme, «La política de reconciliación nacional. Su contenido durante el franquismo, su lectura en la Transición», Ayer, 66, 2, 2007, pp. 20I-225.

Moreno, José Antonio, «La memoria defraudada. Notas sobre el denominado proyecto de Ley de Memoria», en Generaciones y memoria de la represión franquista: un balance de los movimientos por la memoria, Sergio Gálvez (ed.), Dossier monográfico de Hispania Nova. Revista de Historia Contemporánea, 6, 2006, pp. 7II-722. Disponible en: http://hispanianova.rediris. es (I.2.2010).

Muñoz Molina, Antonio, «La nacionalidad del infortunio», El País, 29.IO.I995. Disponible en línea https://elpais.com/diario/1995/II/29/cultura/8I7599616_850215.html (I.2.2010).

Nora, Pierre, Zwischen Geschichte und Gedächtnis, Berlin, Klaus Wagenbach, I990.

Pagès, Pelai, «La represión franquista durante la Guerra Civil», en Represión política, justicia y reparación, Capellà, Margalida \& Ginard, David (eds.), Palma de Mallorca: Edicions Documenta Balear, 2009, pp. 19-42.

Palop, María Eugenia R., «La desmemoria histórica del Partido Popular», eldiario.es del 06.04.2017. Disponible en línea: https://www.eldiario.es/ opinion/zona-critica/desmemoria-historica-partido-popular-franquismo_I29_3472505.html.

Pérez Guirao, Francisco Javier, «Las exhumaciones actuales de fosas comunes de la violencia de retaguardia del golpe militar de 1936 como forma 
de conocimiento del tiempo presente», Historia Actual Online 49 (I), 2019, pp. I29-I38.

Pichler, Georg, «Der Alcázar von Toledo - die Schaffung eines Mythos», en Erinnern und Erzählen. Der Spanische Bürgerkrieg in der deutschen und spanischen Literatur und in den Bildmedien, Bannasch, Bettina \& Holm, Christiane (eds.), Tübingen, Gunter Narr, 2005, pp. I6I-I76.

Pradera, Javier, «Justicia retroactiva», El País, 29.04.2007, p. I2.

Reig Tapia Alberto, Ideología e historia. (Sobre la represión franquista y la guerra civil), Madrid, Akal, 1986.

—. «El asedio del Alcázar: mito y símbolo político del Franquismo», Revista de Estudios Políticos, IOI, I988, pp. IOI-I29.

Resina, Joan Ramón (ed.), Disremembering the Dictatorship. The Politics of Memory in the Spanish Transition to Democracy, Amsterdam, Rodopi, 2000.

Ruiz Torres, Pedro, «Los discursos de la memoria histórica en España», Dossier monográfico de Hispania Nova. Revista de Historia Contemporánea, 7, 2007, pp. 305-334. Disponible en línea: <http://hispanianova.rediris.es>.

Sánchez-Biosca, Vicente (ed.), «La imagen del Alcázar en la mitología franquista», Archivos de la Filmoteca, 35 (Valencia: Generalitat), 200o, pp. 46-I56.

Santos, Félix, «¿A veces el coraje no tiene recompensa?», El País, 28.03.2019, p. II.

Serrano, Rodolfo \& Serrano, Daniel, Toda España era una cárcel, Madrid, Aguilar, 2002.

Silva, Emilio, Las fosas de Franco. Crónica de un desagravio, Madrid, Temas de Hoy, 2005.

Subirats, Eduardo (ed.), Intransiciones. Crítica de la cultura española, Madrid, Biblioteca Nueva, 2002.

Sueiro, Daniel, El Valle de los Caídos. Los secretos de la cripta franquista, Barcelona, Argos Vergara, 1983.

Torres, Rafael, Víctimas de la Victoria, Madrid, Oberon, 2002.

Tranche, Rafael R. \& Sánchez-Biosca, Vicente, NO-DO. El Tiempo y la Memoria, Madrid, Cátedra, 2002.

Vidal, César, Checas de Madrid: las cárceles republicanas al descubierto, Barcelona, Belacqua/ Carroggio, 2003.

Vilarós, Teresa M., El mono del desencanto, Madrid, Siglo XXI, 1998.

Welzer, Harald, "Gedächtnis und Erinnerung», en Handbuch der Kulturwissenschaften. Vol. 3: Themen und Tendenzen, Jaeger, Friedrich \& Rüsen, Jörn (eds.), Stuttgart, J.B. Metzler, 2004, p. I55. 
